\title{
OPEN Regional environmental controllers influence continental scale soil carbon stocks and future carbon dynamics
}

\author{
Daniel Ruiz Potma Gonçalves $\mathbb{1}^{1 凶}$, Umakant Mishra $\mathbb{1}^{2}$, Skye Wills $\mathbb{1}^{3}$ \& Sagar Gautam $\mathbb{1}^{2}$
}

Understanding the influence of environmental factors on soil organic carbon (SOC) is critical for quantifying and reducing the uncertainty in carbon climate feedback projections under changing environmental conditions. We explored the effect of climatic variables, land cover types, topographic attributes, soil types and bedrock geology on SOC stocks of top $1 \mathrm{~m}$ depth across conterminous United States (US) ecoregions. Using $\mathbf{4 5 5 9}$ soil profile observations and high-resolution data of environmental factors, we identified dominant environmental controllers of SOC stocks in 21 US ecoregions using geographically weighted regression. We used projected climatic data of SSP126 and SSP585 scenarios from GFDL-ESM 4 Earth System Model of Coupled Model Intercomparison Project phase 6 to predict SOC stock changes across continental US between 2030 and 2100. Both baseline and predicted changes in SOC stocks were compared with SOC stocks represented in GFDL-ESM4 projections. Among 56 environmental predictors, we found 12 as dominant controllers across all ecoregions. The adjusted geospatial model with the 12 environmental controllers showed an $R^{2}$ of 0.48 in testing dataset. Higher precipitation and lower temperatures were associated with higher levels of SOC stocks in majority of ecoregions. Changes in land cover types (vegetation properties) was important in drier ecosystem as North American deserts, whereas soil types and topography were more important in American prairies. Wetlands of the Everglades was highly sensitive to projected temperature changes. The SOC stocks did not change under SSP126 until 2100, however SOC stocks decreased up to $21 \%$ under SSP585. Our results, based on environmental controllers of SOC stocks, help to predict impacts of changing environmental conditions on SOC stocks more reliably and may reduce uncertainties found in both, geospatial and Earth System Models. In addition, the description of different environmental controllers for US ecoregions can help to describe the scope and importance of global and local models.

Soils store the largest amount of carbon in terrestrial ecosystems containing around $1500 \mathrm{Pg} C\left(\mathrm{Pg} ; 1 \mathrm{Pg}=10^{15} \mathrm{~g}\right)$ soil organic carbon (SOC) in top $1 \mathrm{~m}$ depth $^{1,2}$. Understanding the relationship between SOC and its environmental controllers is key for accurately predicting climate and land use change impacts on SOC and reducing uncertainties in large scale carbon climate feedback projections.

Earth System Models (ESMs) ${ }^{3}$ are used to predict the global carbon climate feedbacks and simulate the future state of soils and ecology. Despite their key roles in determining the spatial heterogeneity of SOC and regulating the rate of SOC decomposition, many environmental factors that regulate soil formation are not adequately represented in current land surface models ${ }^{4}$. As a result, current land surface models poorly represent baseline SOC spatial heterogeneity ${ }^{4,5}$ and show large uncertainties in predicting future carbon climate feedbacks ${ }^{6}$. Burke, et al. ${ }^{7}$ reported that the quantity, spatial distribution, and decomposability of SOC stocks accounted for half of the overall uncertainty in predicting future carbon climate feedbacks and associated climate changes. Therefore, to reduce the uncertainty in future carbon climate feedback projections, it is critical to appropriately represent environmental controllers and the spatial heterogeneity of SOC in land surface models. One way to improve

\footnotetext{
${ }^{1}$ Department of Fitotechnics and Plant Health, Universidade Estadual de Ponta Grossa, 4748, General Carlos Cavalcanti Avenue, Ponta Grossa, Paraná 84030-900, Brazil. ${ }^{2}$ Bioscience Division, Sandia National Laboratory, Livermore, CA 94550, USA. ${ }^{3}$ National Soil Survey Center, USDA- Natural Resource Conservation Center, 100 Centennial Mall North, Lincoln, NE 68508, USA. ${ }^{\circledR}$ email: drpgoncalves@uepg.br
} 
the spatial heterogeneity of SOC stocks in land surface models is to quantify and represent the environmental controls on SOC stocks consistent with field observations.

Statistical geospatial modeling can be used to quantify the heterogeneity of environmental controllers on SOC stocks from regional to national and global scales. Also, environmental controllers' spatial gradient can be used in a space-for-time substitution approach to predict the spatiotemporal variation in SOC stocks ${ }^{8}$. O'Rourke, et al. ${ }^{9}$ stated that linking specific environmental controllers to SOC functions can be a way to toward more realistic projections in ESMs. Examples of this approach were applied for Australian ${ }^{10}$, Brazilian ${ }^{11}$ and other soils using geospatial modelling. The same way Weintraub, et al. ${ }^{12}$ highlighted the potential of soil observation networks to accelerate process representation in SOC models and improve our current capacity to make predictions.

In this study we used a database composed of 4559 soil profile observations in conterminous US and 56 environmental predictors representing climate, topography, soil type, geology, land use and water dynamics to fit a geographically weighted regression model. We used the model to predict and generate maps of current and future SOC in 21 US ecoregions. The maps were generated considering current and two shared socioeconomic pathways SSP126 and SSP585 from GFDL-EMS4 of Coupled Model Intercomparison Project phase 6 (CMIP6), corresponding of IPCC RCP 2.6 and 8.5 scenarios. To produce the SSP 126 and SSP585 pathways maps, we used future temperature and precipitation regimes from GFDL-EMS4 predictions in conterminous US. Finally, the results were compared with total SOC stocks from GFDL-ESM4 model predictions.

\section{Results}

The chosen model included 12 individual variables from the original 56 (Table 1) as yearly averages: Temperature, Precipitation, Atmosphere Net Radiation, Net Primary Productivity, (Normalized difference vegetation index) NDVI, Forest and Pastureland cover classes, Inceptisols, Vertisols, Ultisols, Spodosols, and Mollisols soil classes. The obtained SOC stocks map for all ecoregions (Figs. 1, 2) showed higher values in the north east and pacific north west, forested mountainous areas, south Florida, and central US prairies. The regions with highest mean SOC stocks were Everglades (777 Mg/ha), Mixed Wood Shield (660 Mg/ha), Mississippi Alluvial and Southeastern USA Plains (519 Mg/ha), Atlantic Highlands (456 Mg/ha) and Mixed Wood Plains (352 Mg/ha) (Table 2). The lowest values were found in Warm Deserts and Texas-Louisiana Coastal Plain, less than $65 \mathrm{Mg} \mathrm{ha}^{-1} \mathrm{C}$.

Predicted SOC stocks using geographically weighted regression (GWR) showed coefficient of variation $\left(\mathrm{R}^{2}\right)$ of 0.48 (quasi-global). The GWR approach consistently underestimated the SOC stocks, bias is higher in the ecoregion with higher observed SOC stocks (Table 2). The bias was 83 and $71 \%$ in the Everglades and OzarkOuachita-Appalachian Forests; all other regions had bias less than 43\%. Six Ecoregions presented model bias lower than 15. The model residual was not distributed homogeneously inside ecoregions, but some regions presented higher model bias than others (e.g., Mississippi delta and Warm Deserts SOC stocks were under and overestimated respectively) (Fig. 2).

SOC stocks were controlled by different environmental factors across US ecoregions (Fig. 3). The ecoregions, Mediterranean California, Cold Desert, Upper Gila Mountain, Warm Desert, Western Cordillera, and SouthCentral Semiarid Prairies were closely related to net primary production and vegetation types. In the Southern plains ecosystems, precipitation and net solar radiation were good predictors, and Everglades showed a different dynamics, presenting mean temperature and NDVI as good predictors. There was not a group of predictors highlighted for the other Ecoregions (Fig. 3). Mean temperature was positively related with SOC stocks in Everglades, Texas-Louisiana Costal Plains, Mediterranean California and Mississippi Alluvial and Southeastern USA Plains, on the other Ecoregions temperature increases resulted in reduction of SOC stocks. In Texas-Louisiana Coastal Plains and Mediterranean California SOC stocks were more sensitive to precipitation amount, which indicated it is a major diver of SOC stocks in warm and dry conditions. In the Everglades, Central USA Plains, Upper Gila Mountains and Mixed Wood Shield precipitation was negatively related on SOC stocks.

The prediction for SSP126 and SSP585 scenarios using GFDL-ESM4 projection of temperature and precipitation showed a decrease in SOC stocks. The magnitude was about $4 \%$ to $7 \%$ (3252 and $5470 \mathrm{Tg})(\mathrm{Tg} ; 1$ $\mathrm{Tg}=10^{12} \mathrm{~g}$ ) respectively (Table 2, Fig. 4). Both prediction maps (Fig. 4) showed an increase in SOC for northern prairies and Florida ecoregions. Other ecoregions showed decrease in SOC stocks indicating sensitivity of those ecosystems to future climatic changes. However, uncertainties related to sea level rise ${ }^{13,14}$, especially on SSP585 scenario, which predicts a raise between 60 and $110 \mathrm{~cm}$ util 2100, make it difficult to precisely determine SOC decreases in Florida Lowlands as this region is expected to lose land mass. Four ecoregions showed an increase in SOC stocks, Everglades, Mixed Wood Shield, Mississippi Alluvial and Southeastern USA Plains and Warm Deserts, it was most pronounced in the Everglades with a $192 \%$ increase in SOC. Model projections showed a reduction in SOC stocks for both lower and higher emission scenarios (SSP126 and SSP585) (Table 3, Fig. 5). The changes were not significant for SSP 126 with approximately 2\% change. In contrast, for the SSP 585 scenario, the reduction ranged between $5 \%$ in 2030 to $21 \%$ in 2100 . Although the highest value of SOC observed in SSP585 (4507 Mg ha-1) was almost double the SSP126 (2506 $\left.\mathrm{Mg} \mathrm{ha}^{-1}\right)$, total SOC stocks (the sum of all pixels in the maps) was lower (Fig. 4). We also compared our SOC results with the GFDL-ESM4 projections. Despite differences in the model's resolution ( $800 \mathrm{~m}$ for geospatial model and $0.5^{\circ}$ for GFDL-ESM4) and particularities of process representation (e.g., GFDL-ESM4 does not simulate for wetlands and peatlands); it also showed a decrease in SOC for SSP585 pathway, being more pronounced in northwest part of US (Supplementary Fig. 1). The lowest emission scenario (SSP126) maintained the current SOC stocks.

\section{Discussion}

Our baseline SOC stock distribution showed similar spatial distribution as the published RaCA map produced using an ordinary kriging spatial interpolation approach ${ }^{15}$. The high values of SOC stocks in coastal environments showed the high capacity of wetlands like the Everglades to store SOC. Wetlands potential for store SOC 


\begin{tabular}{|c|c|c|c|}
\hline Environmental predictor & Brief description & Data source & Resolution \\
\hline \multicolumn{4}{|l|}{ Climate predictors } \\
\hline Precipitation & $\begin{array}{l}\text { 30-yr (1981 to 2010) annual average precipita- } \\
\text { tion }\end{array}$ & http://www.prism.oregonstate.edu/normals & $800 \mathrm{~m}$ \\
\hline Minimum temperature & $\begin{array}{l}\text { 30-yr (1981-2010) annual average minimum } \\
\text { temperature }\end{array}$ & http://www.prism.oregonstate.edu/normals & $800 \mathrm{~m}$ \\
\hline Mean temperature & $\begin{array}{l}\text { 30-yr (1981-2010) annual average tempera- } \\
\text { ture }\end{array}$ & http://www.prism.oregonstate.edu/normals & $800 \mathrm{~m}$ \\
\hline Maximum temperature & $\begin{array}{l}\text { 30-yr (1981-2010) annual average maximum } \\
\text { temperature }\end{array}$ & http://www.prism.oregonstate.edu/normals & $800 \mathrm{~m}$ \\
\hline Dew point temperature & $\begin{array}{l}\text { 30-yr (1981-2010) annual average dew point } \\
\text { temperature }\end{array}$ & http://www.prism.oregonstate.edu/normals & $800 \mathrm{~m}$ \\
\hline Minimum vapor pressure deficit & $\begin{array}{l}\text { 30-yr (1981-2010) minimum vapor pressure } \\
\text { deficit }\end{array}$ & http://www.prism.oregonstate.edu/normals & $800 \mathrm{~m}$ \\
\hline Maximum vapor pressure deficit & $\begin{array}{l}\text { 30-yr (1981-2010) maximum vapor pressure } \\
\text { deficit }\end{array}$ & http://www.prism.oregonstate.edu/normals & $800 \mathrm{~m}$ \\
\hline Potential evapotranspiration & $\begin{array}{l}\text { 30-yr (1970-2000) potencial evapotranspora- } \\
\text { tion }\end{array}$ & https://cgiarcsi.community/ & $0.25^{\circ}$ \\
\hline Net radiation & 2017 yearly average net radiation & https://neo.sci.gsfc.nasa.gov/ & 30 arc-seconds $(\approx 1 \mathrm{~km}$ at equator $)$ \\
\hline \multicolumn{4}{|l|}{ Land use and land cover predictors } \\
\hline Ecological region ${ }^{*}$ & Ecological zone map at level II & $\begin{array}{l}\text { https://www.epa.gov/eco-research/ecoregions- } \\
\text { north-america }\end{array}$ & $100 \mathrm{~m}$ \\
\hline Net primary production & Annual terrestrial primary production & https://neo.sci.gsfc.nasa.gov/ & $0.25^{\circ}$ \\
\hline $\begin{array}{l}\text { Normalized difference vegetation index } \\
\text { (NDVI) }\end{array}$ & $\begin{array}{l}\text { Annual Normalized difference veg- } \\
\text { etation index (Calculated as (NIR-RED)/ } \\
\text { (NIR + RED), where, NIR is near-infrared } \\
\text { band) }\end{array}$ & https://neo.sci.gsfc.nasa.gov/ & $0.25^{\circ}$ \\
\hline National land cover database (6 classes) & Land cover of the United States for 2011 & https://www.mrlc.gov/nlcd2011.php & $30 \mathrm{~m}$ \\
\hline \multicolumn{4}{|l|}{ Topographic predictors } \\
\hline Elevation (DEM) & Land surface elevation & $\begin{array}{l}\text { https://www.usgs.gov/core-science-systems/ } \\
\text { national-geospatial-program/ }\end{array}$ & $30 \mathrm{~m}$ \\
\hline Aspect & Compass direction that the slope faces & Derived from DEM & $30 \mathrm{~m}$ \\
\hline Slope & Raise or fall of land surface & Derived from DEM & $30 \mathrm{~m}$ \\
\hline Plan curvature & $\begin{array}{l}\text { Terrain curvature that is perpendicular to } \\
\text { maximum slope direction }\end{array}$ & Derived from DEM & $30 \mathrm{~m}$ \\
\hline Profile curvature & $\begin{array}{l}\text { Terrain curvature that is parallel to maximum } \\
\text { slope direction }\end{array}$ & Derived from DEM & $30 \mathrm{~m}$ \\
\hline Total curvature & Combination of plan and profile curvature & Derived from DEM & $30 \mathrm{~m}$ \\
\hline \multicolumn{4}{|l|}{ Soil and bedrock predictors } \\
\hline Soil orders (10 orders) & Taxonomy soil order & $\begin{array}{l}\text { https://www.nrcs.usda.gov/wps/portal/nrcs/ } \\
\text { detail/soils/home/ }\end{array}$ & $100 \mathrm{~m}$ \\
\hline Bedrock geology (23 classes) & Taxomony of bedrock geology & $\begin{array}{l}\text { https://www.usgs.gov/products/maps/geolo } \\
\text { gic-maps }\end{array}$ & $1000 \mathrm{~m}$ \\
\hline
\end{tabular}

Table 1. Environmental predictors used for the geospatial modelling process. ${ }^{*}$ The United States ecoregions were not used as environmental predictors, but for organize the various ecosystems prediction dynamics.

was also highlighted in other studies, Hinson, et al. ${ }^{16}$ estimated $1153-1359 \mathrm{Tg}$ of SOC in the $0-100 \mathrm{~cm}$ in US peatlands, or about $19 \%$ of US SOC stocks. Similarly, the model bias in the SOC estimation for ecoregions with higher SOC stock were also documented in earlier studies ${ }^{16}$. Net primary production importance as predictor for SOC stocks in driest ecosystems like the North American deserts (Fig. 3) may be related to its sparse vegetation. Thereby, probably as the carbon input to soil is low compared to other ecosystems, the net primary production impact was captured as a limiting factor.

In this study, climatic variables were important predictors of SOC stocks in some ecoregions such as the Southeastern USA Plains and Everglades, showing the sensitivity of these ecosystems to projected climate change estimates. The higher influence of temperature and precipitation on SOC of wetlands indicate vulnerability of these system to future climate changes ${ }^{17,18}$. Although climate factor has been reported in this and other studies as important predictors for SOC stocks, it may be a proxy for geochemical factors that affect SOC directly like soil texture and microbial activity. Geochemical factors were also reported as important predictors for SOC stock in other studies ${ }^{19}$. Yang, et al. ${ }^{20}$ found soil moisture and texture as major drivers to explain SOC distribution in Tibetan plateau and Giardina, et al. ${ }^{21}$ suggested the change in soil respiration due to increased temperature and precipitation as major factor to determine the change in SOC stocks.

Some other factors used to predict SOC stocks are also expected to change in the future (e.g., the location of wetlands is expected to change with the change in hydrologic regime and wildfires may increase in some regions due to temperature raise and reduced precipitation). According to the fifth IPCC report ${ }^{18}$, the Southern US ecoregions are expected to get drier, opposite to the Everglades and the central region that are expected to 


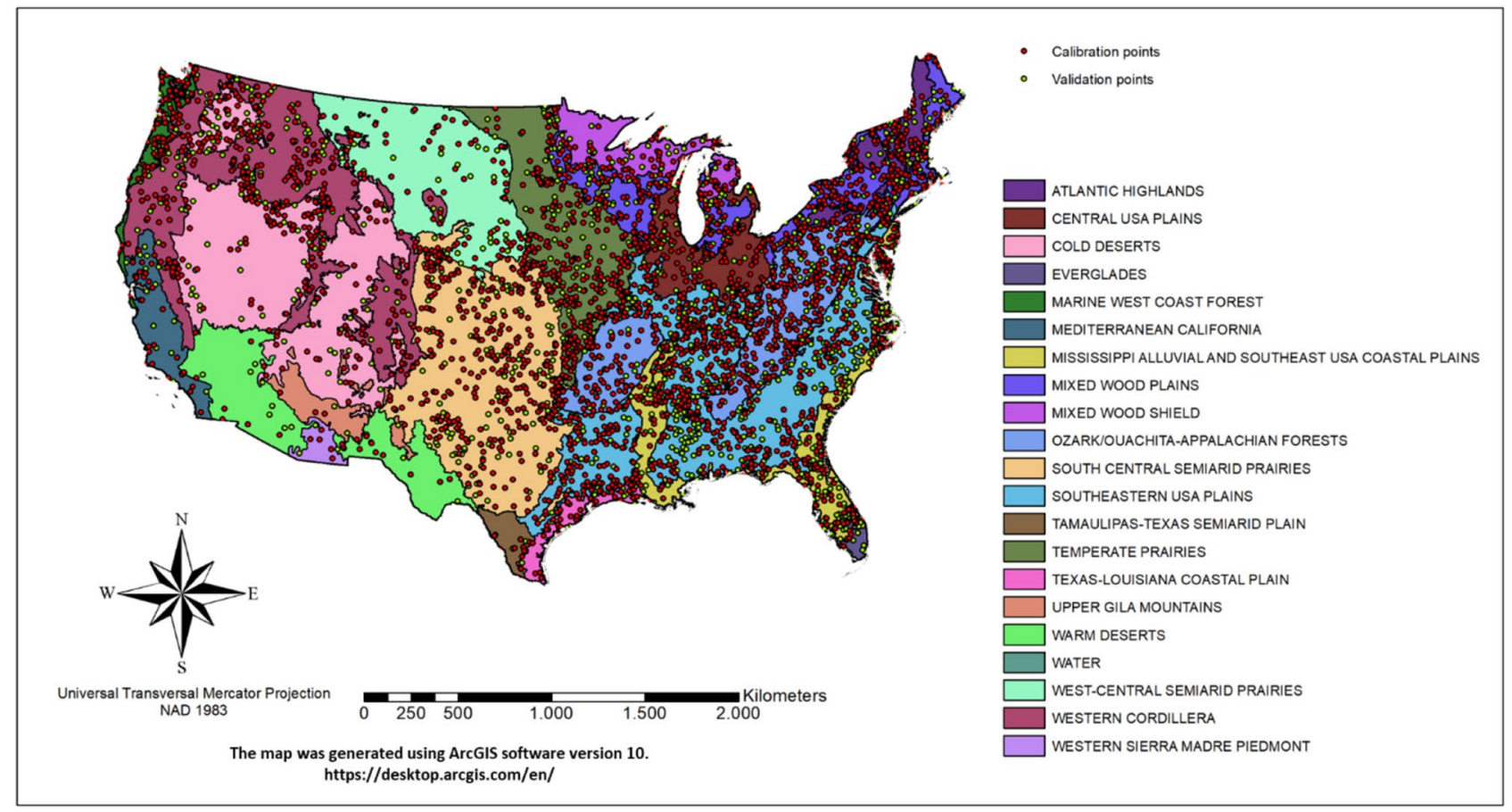

Figure 1. United States of America level II ecoregions, and the RaCA datapoints distribution, the red and green points were chosen for calibration and validation of the geographically weighted regression model respectively.
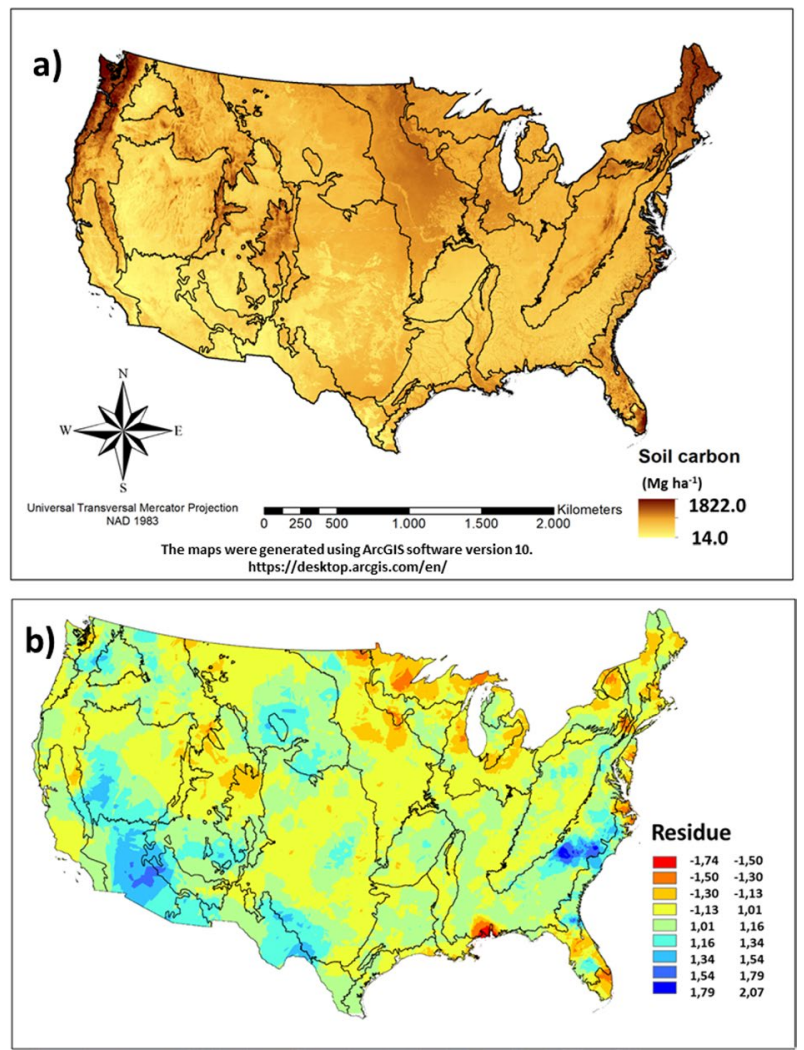

Figure 2. Maps of soil organic carbon stocks distribution over continental United States of America obtained from the geographically weighted regression model (a) and model residuals (b). The black lines represent the borders of level II ecoregions described in Fig. 1. 


\begin{tabular}{|c|c|c|c|c|c|c|}
\hline Ecoregion & $\begin{array}{l}\text { Soil carbon stock (Mg } \\
\left.\text { ha }^{-1}\right)\end{array}$ & Soil carbon stock $(\mathrm{Tg})$ & $\begin{array}{l}\text { Soil carbon stock } \\
\text { SSP126 (Tg) }\end{array}$ & $\begin{array}{l}\text { Soil carbon stock } \\
\text { SSP585 }(\mathrm{Tg})\end{array}$ & $\begin{array}{l}\text { Model residue (Mg } \\
\left.\mathrm{ha}^{-1}\right)\end{array}$ & Model residue (\%) \\
\hline Everglades & 776.6 & 304.9 & 627.3 & 970.0 & -643.2 & 82.8 \\
\hline Mixed Wood Shield & 661.1 & 2539.5 & 2603.5 & 2663.5 & -265.5 & 40.2 \\
\hline $\begin{array}{l}\text { Mississippi Alluvial and } \\
\text { Southeast USA Coastal } \\
\text { Plains }\end{array}$ & 519.3 & 3584.5 & 4220.1 & 4613.8 & -210.0 & 40.4 \\
\hline Atlantic Highlands & 457.0 & 2949.8 & 2652.5 & 2405.5 & -132.4 & 29.0 \\
\hline $\begin{array}{l}\text { Marine West Coast } \\
\text { Forest }\end{array}$ & 403.5 & 2101.9 & 2002.5 & 1939.6 & -104.7 & 25.9 \\
\hline Mixed Wood Plains & 352.4 & 5266.9 & 5000.3 & 4772.7 & -151.1 & 42.9 \\
\hline Central Usa Plains & 207.9 & 2481.3 & 2344.1 & 2241.3 & -74.2 & 35.7 \\
\hline Temperate Prairies & 191.6 & 7289.2 & 7147.4 & 7012.0 & -21.9 & 11.4 \\
\hline Western Cordillera & 170.5 & 9557.8 & 8751.5 & 8177.0 & -56.2 & 33.0 \\
\hline $\begin{array}{l}\text { Texas-Louisiana Coastal } \\
\text { Plain }\end{array}$ & 163.7 & 631.2 & 633.4 & 625.2 & -41.2 & 25.2 \\
\hline $\begin{array}{l}\text { Ozark/Ouachita-Appala- } \\
\text { chian Forests }\end{array}$ & 123.5 & 4617.0 & 3881.1 & 3488.3 & -87.8 & 71.1 \\
\hline $\begin{array}{l}\text { West-Central Semiarid } \\
\text { Prairies }\end{array}$ & 102.8 & 5637.8 & 5603.5 & 5566.6 & -7.3 & 7.1 \\
\hline Upper Gila Mountains & 100.4 & 708.7 & 683.5 & 664.0 & -34.2 & 34.0 \\
\hline Cold Deserts & 97.8 & 6927.5 & 6447.2 & 6106.8 & -27.4 & 28.0 \\
\hline Southeastern Usa Plains & 97.5 & 8359.9 & 8115.0 & 7892.2 & -11.6 & 11.9 \\
\hline $\begin{array}{l}\text { Mediterranean Cali- } \\
\text { fornia }\end{array}$ & 91.2 & 1134.4 & 1120.3 & 1129.2 & -22.9 & 25.1 \\
\hline $\begin{array}{l}\text { South Central Semiarid } \\
\text { Prairies }\end{array}$ & 87.0 & 8184.3 & 7283.2 & 6703.1 & -24.7 & 28.4 \\
\hline $\begin{array}{l}\text { Western Sierra Madre } \\
\text { Piedmont }\end{array}$ & 76.5 & 2339.7 & 2262.6 & 2215.0 & -6.1 & 8.0 \\
\hline $\begin{array}{l}\text { Tamaulipas-Texas Semi- } \\
\text { arid Plain }\end{array}$ & 61.7 & 368.9 & 332.5 & 300.0 & -2.0 & 3.3 \\
\hline Warm Deserts & 48.0 & 223.1 & 244.9 & 264.0 & 0.6 & 1.2 \\
\hline Total (Pg) & & $75,208.2$ & $71,956.2$ & $69,749.7$ & & \\
\hline
\end{tabular}

Table 2. Soil carbon stocks and model residue for US main ecoregions.

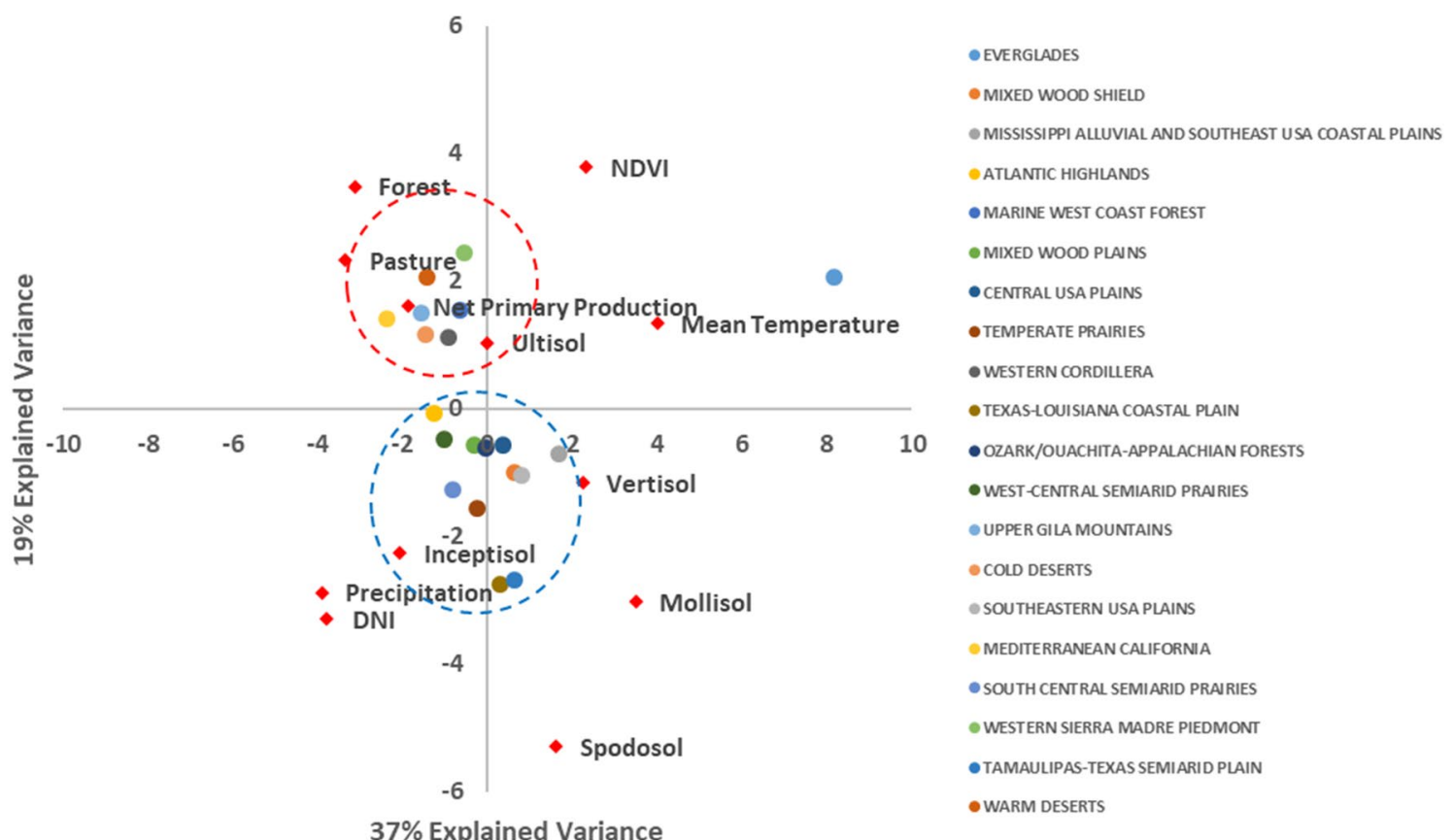

Figure 3. Principal component analysis relating the selected environmental predictors and the United States of America level II ecoregions. 
Soil carbon, SSP585, 2100.
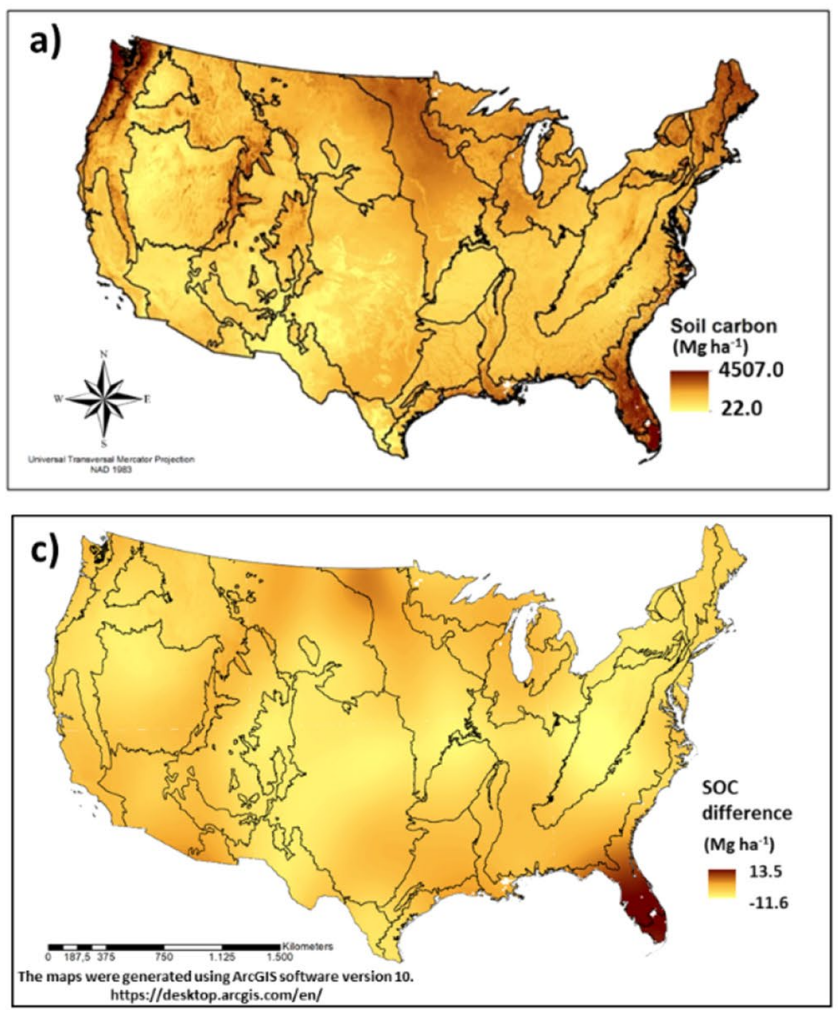

Soil carbon, SSP126, 2100.

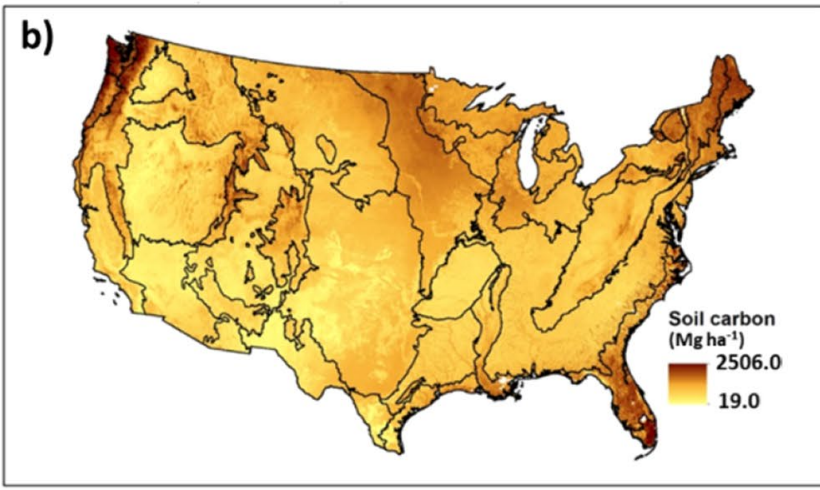

d)

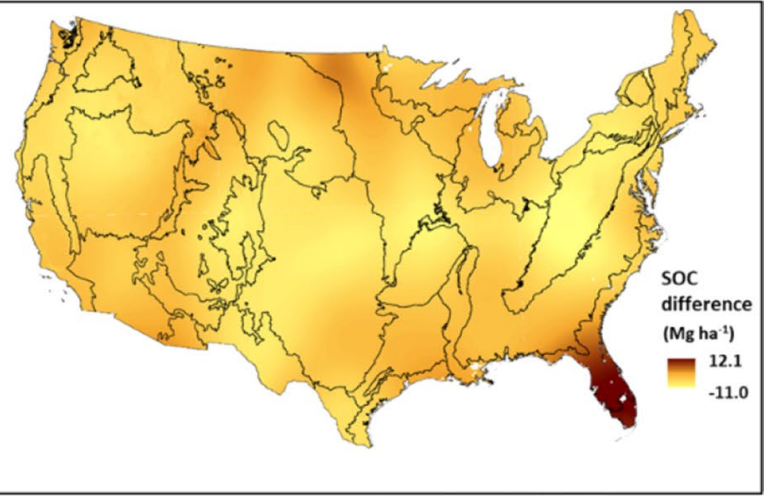

Figure 4. Soil organic carbon stocks prediction for 2100 in SSP585 (a) and SSP126 (b) scenarios using GFDLESM4 model of couple model intercomparison project phase 6 (CMIP6) climate projections data and the calculated difference compared with 2017 soil organic carbon stocks for SSP585 (c) and SSP126 (d). The black lines represent the borders of level II ecoregions described in Fig. 1.

\begin{tabular}{|c|c|c|c|c|c|c|c|c|c|c|c|c|}
\hline \multirow[b]{3}{*}{ Year } & \multicolumn{4}{|c|}{ SSP126 } & \multicolumn{4}{|c|}{ SSP585 } & \multicolumn{4}{|c|}{ Current scenario } \\
\hline & Min & $\operatorname{Max}$ & Mean & \multirow{3}{*}{\begin{tabular}{|l|} 
Total C \\
$(\mathrm{Pg})$ \\
\end{tabular}} & Min & $\operatorname{Max}$ & Mean & \multirow{3}{*}{\begin{tabular}{|l} 
Total C \\
$(\mathbf{P g})$ \\
\end{tabular}} & Min & Max & Mean & \multirow{2}{*}{\begin{tabular}{|l|} 
Total C \\
$(\mathbf{P g})$ \\
\end{tabular}} \\
\hline & \multicolumn{3}{|c|}{\begin{tabular}{|l} 
Soil C stocks (Mg/ha) \\
\end{tabular}} & & \multicolumn{3}{|c|}{ Soil C stocks (Mg/ha) } & & \multicolumn{3}{|c|}{ Soil C stocks (Mg/ha) } & \\
\hline 2017 & & & & & & & & & 0.2 & 24.3 & 96.3 & 74.5 \\
\hline 2030 & 11.3 & 2895.3 & 90.0 & 69.6 & 11.3 & 4106.4 & 91.8 & 71.0 & & & & \\
\hline 2040 & 11.6 & 3920.2 & 95.1 & 73.6 & 11.4 & 4409.1 & 91.4 & 70.8 & & & & \\
\hline 2050 & 11.4 & 3074.9 & 92.8 & 71.8 & 11.3 & \begin{tabular}{|l|}
8896.7 \\
\end{tabular} & 88.3 & 68.4 & & & & \\
\hline 2060 & 11.4 & 5626.1 & 92.0 & 71.2 & 11.2 & 6959.9 & 86.9 & 67.3 & & & & \\
\hline 2070 & 11.5 & 3776.5 & 92.0 & 71.2 & 11.4 & 6106.7 & 85.2 & 66.0 & & & & \\
\hline 2080 & 11.3 & 4445.1 & 92.1 & 71.3 & 11.4 & $11,526.6$ & 83.4 & 64.6 & & & & \\
\hline 2090 & 11.4 & 2437.2 & 91.2 & 70.6 & 11.3 & $18,452.6$ & 81.8 & 63.3 & & & & \\
\hline 2100 & 11.4 & 2149.4 & 94.5 & 73.2 & 11.3 & $13,047.4$ & 76.0 & 58.8 & & & & \\
\hline
\end{tabular}

Table 3. Soil carbon stocks predictions for every 10 years between 2030 and 2100.

experience higher precipitation. Although wetlands are expected to change due to increased $\mathrm{CO}_{2}$ concentration, precipitation change, frequent extreme events (e.g., floods, storms), sea level rise, frequent wildfires, increase methane emissions and temperature, the effect of climate change on SOC stocks is still not well known ${ }^{22}$. The complexity of the water cycle makes it difficult to capture all the feedbacks and peatlands/wetlands may emit more carbon than sequester ${ }^{17}$. It's not clear whether climate change will increase or decrease wetland area over continental US, but the net primary production should increase ${ }^{23}$. Primary vegetation is expected to move South to North in continental US due to increase in temperature in higher latitude ${ }^{23,24}$. Isolated events like wildfires has increase in the last years in west conterminous US, resulting in tree mortality ${ }^{25}$. Although carbon emission from wildfires is certain, its effect is still not well understood because of vegetation regeneration ${ }^{26}$. On the other hand, US deserts may increase biomass production ${ }^{18}$. 


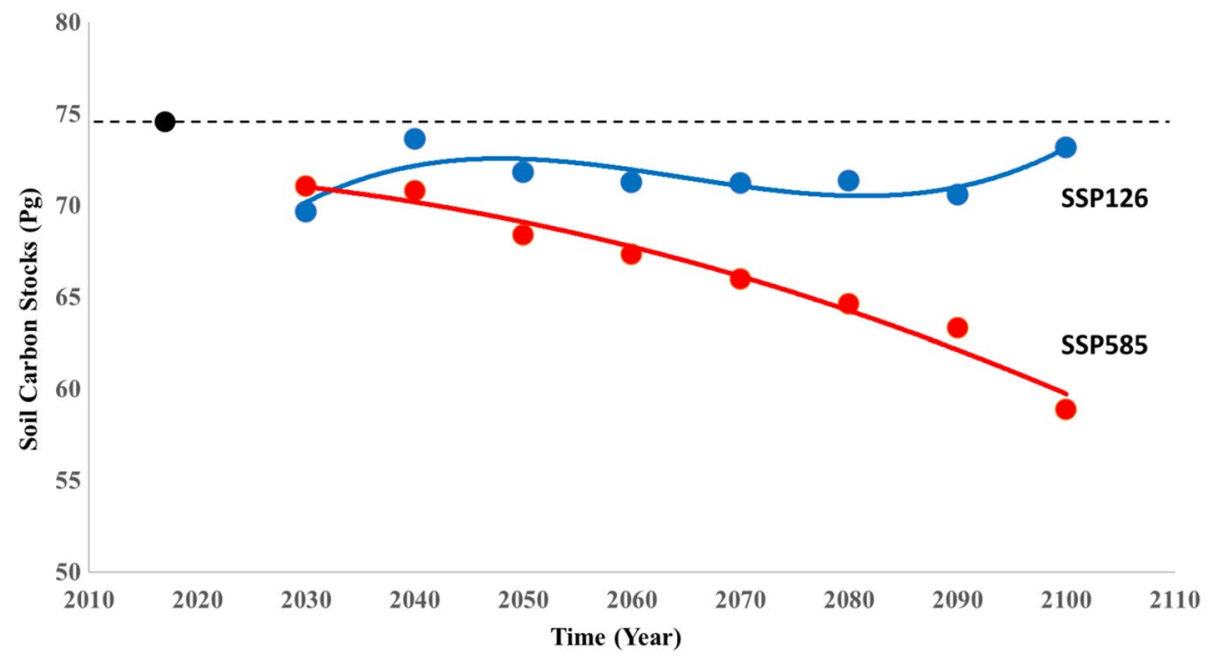

Figure 5. Soil organic carbon stocks predictions in continental United States of America for every ten years between 2020 and 2100 for SSP126 in blue and SSP585 in red.

The extreme SOC values showed no difference for record low between SSP126 and 585, but the record high was 41 to $500 \%$ higher in SSP585 compared to 126 . Soil organic carbon stocks reduction accounting for conterminous US for SSP585 was highly pronounced compared to 126, highlighting SOC sensitivity to climatic factors. The main exception, Florida, showed an increase in SOC stocks (Table 2), that can be explained by the high sensitivity of this region to mean temperature (Fig. 3). Temperature and precipitation changing are expected to influence other factors such as vegetation and sea level, influencing SOC stocks. These changes, as well its effect over SOC stocks, takes time, since SOC stabilization in soils is a dynamic process that reaches a new equilibrium stage on ecosystems after years or even decades from perturbation. These factors can add uncertainties when using a spatial based approach instead of temporal ${ }^{8}$. Although, when comparing our results with GFDL-ESM4 model simulations that accounted for carbon climate feedbacks, the same pattern was observed, considering total SOC stocks reduction for SSP126 and SSP585.

Although SOC dynamics may be similarly affected by the explored predictors in all the studied region, our results indicated relative importance, since SOC stocks were limited for different predictors across different ecoregions. This way, changes in SOC stocks inside the same ecoregion was related to variation on the specific limiting factors. This is especially important for improve soil process representations in Earth System Models, where treat specific important factors more accurately in different ecoregions can be a strategy for improve models' predictions. Higher precipitation and lower temperatures were associated with higher levels of SOC stocks in majority of ecoregions. Changes in land cover types (vegetation properties) was important in drier ecosystem as North American deserts, whereas soil types and topography were more important in American prairies. Wetlands of the Everglades was highly sensitive to projected temperature changes. Although represent these behaviors in Earth System Models can be a way to produce more accurate global predictions, interaction among factors can result in emergent complex interactions, difficult to derive especially when data is a limiting factor ${ }^{12}$. This shows the importance of local models as an alternative to produce more accurate predictions on its represented region. The development of appropriate observation networks may provide data for the development, benchmarking, and validation of statistical and process-based models, increasing our understanding of SOC cycle at different scales and improving the predictive accuracy ${ }^{12,27}$. In addition, the description of different environmental controllers for US ecoregions can help to describe the scope and importance of global and local models.

\section{Methods}

Study area and soil carbon profiles and observations. We performed this study in the continental US using 4559 georeferenced soil profile observations obtained from the Rapid Carbon Assessment ${ }^{28}$ project (Fig. 1). The soil profiles were distributed across the conterminous US covering 21 existing ecoregions described by the United States Environmental Protection Agency (EPA, https://www.epa.gov/eco-research/ecoregions) ${ }^{29}$, land cover and soil types. A total of 31,472 samples describe the soil profiles, $77 \%(24,192)$ were distributed between 0 and $100 \mathrm{~cm}$, which was used for this study. Thus, approximately five samples per soil profile were used for calculating soil carbon stocks at $0-100 \mathrm{~cm}$ depth. SOC was measured by dry combustion and bulk density was modelled ${ }^{30}$. For calculating SOC stocks for each pedon/profile, a fixed depth approach was used. A more complete description of the methods used to analyze the samples can be obtained in the Rapid Carbon Assessment: Methodology, Sampling and Summary ${ }^{15}$. The measured SOC ranged from 1.37 to $11,981.0 \mathrm{Mg} \mathrm{C} \mathrm{ha}^{-1}$ and with a mean of $209.6 \mathrm{Mg} \mathrm{C} \mathrm{ha}^{-1}$. The lowest stocks were measured in desert biomes and highest in wetlands. The SOC stocks showed a unimodal positively skewed distribution to normalize the data for the modelling activities we applied a box-cox transformation. 
Environmental variables. Soil orders were obtained from the conterminous United States digital soil map derived from the gridded Soil Survey Geographic Database (gSSURGO) in $30 \mathrm{~m}$ resolution (https://data.nal. usda.gov/dataset/gridded-soil-survey-geographic-database-gssurgo) and aggregated into 10 soil orders: Alfisols, Andisols, Aridisols, Entisols, Histosols, Inceptisols, Mollisols, Spodosols, Ultisols, Vertisols. We obtained the bedrock geology types information ${ }^{31}$ from the United States Geological Survey (https://www.usgs.gov/produ cts/maps/geologic-maps) map with $1 \mathrm{~km}$ resolution and aggregated the main geological features into 23 groups.

We obtained 30 years (1981-2010) mean annual average data of precipitation, maximum, minimum and mean temperature, mean dew point temperature and minimum and maximum vapor pressure deficit at $800 \mathrm{~m}$ resolution from PRISM website (http://www.prism.oregonstate.edu/normals/). Monthly mean net radiation was derived from NASA (https://neo.sci.gsfc.nasa.gov/) with 0.25 degrees resolution and compiled into average annual net radiation datasets. The potential evapotranspiration maps were acquired from Consultative Group on International Agricultural Research-Consortium for Spatial Information (https://cgiarcsi.community/) with spatial resolution of 30 arc-seconds $(\approx 1 \mathrm{~km}$ at equator). The mean annual NDVI and net primary productivity datasets were obtained from NASA Earth observations at $10 \mathrm{~km}$ resolution (https://neo.sci.gsfc.nasa.gov/). We obtained US land cover data of $30 \mathrm{~m}$ resolution from multi resolution land characteristics (https://www.mrlc.gov/ nlcd2011.php) and aggregated land cover types into 6 major categories, briefly: Open Water and Perennial Ice/ Snow were grouped as Water, Developed Open Space, Low, Medium and High Intensity were grouped as Urban, Deciduous, Evergreen and Mixed Forest were grouped as Forest, Woody and Emergent Herbaceous Wetlands were grouped as Wetlands and the other classes were Rock, Cropland, Grassland, Pasture and Scrub. The Water, Urban and Bare Rock Land cover types were excluded from the analysis. All the chosen categorical variables were treated as individual predictors (e.g., We considered Alfisols, Andisols, Forest and Croplands as four predictors).

We obtained a digital elevation model (DEM) with $30 \mathrm{~m}_{\text {resolution }}{ }^{32}$ from US Geological Survey Database (https://www.usgs.gov/core-science-systems/national-geospatial-program/) and derived the following terrain attributes: Elevation, aspect, slope, plan curvature, profile curvature and total curvature in GIS environment using ArcGIS v $10^{33}$. The environmental predictors used are described in Table 1 and the ecoregion used for group the observations in Fig. 1. All the environmental dataset raster maps were resampled to $800 \mathrm{~m}$, the climatic data resolution, and the values were extracted at SOC sample points and used in further analysis.

Data pre-processing and geospatial model fit. The SOC data in the same ecoregion that were outside of $1.5^{\star} \mathrm{IQR}$ where removed as outliers. First, we used plots to identify non-linear relationships that could not be captured by linear modelling. Further, to avoid including unnecessary environmental predictors in the model we generated Pearson correlation coefficients for all numerical predictors paired in a correlation matrix. When the pair showed a high correlation coefficient $(r>0.70)$ one of the predictors was removed, we choose keeping the one which its effect over SOC dynamics is better known according to current theory. To measure the model fit, we divided the database into training $(75 \% ; 3419$ samples) and testing $(25 \% ; 1140$ samples $)$ datasets. The training dataset was used to fit the model and testing set to measure the model prediction capacity. We treated the nominal/categorical variables as dummy variables (e.g., 0 or 1 ).

After pre-processing, we fitted multiple regression models and used three selection criteria to choose the optimum set of linear predictors, variable significance according to $\mathrm{F}$ test at $p<0.05$, best subset ${ }^{34}$, and $\mathrm{R}^{2}$. Using the significant environmental predictors, we fitted a GWR model, the adaptative bandwidth was chosen based on Akaike Information Criterion minimization ${ }^{35}$. Briefly, GWR works as a multiple linear regression that fits unique parameters for every feature in the dataset. Consequently, the result is a model with the same predictors for SOC stocks and different coefficients ( $\beta$ values) for each local and ecoregion. The spatial variation of the coefficients can be used to explore local ecoregion specific controllers for SOC stocks. A more complete description of GWR approach can be found in Fotheringham book ${ }^{36,37}$. The model was then applied to the test dataset which had an $\mathrm{R}^{2}$ of 0.48 . We then used the GWR model to generate a SOC stocks map in in $\mathrm{Mg} \mathrm{ha}^{-1}{ }^{33}$. Using the coefficients adjusted for the predictor variables in the GWR model, we calculated a correlation matrix and performed a principal component analysis to visualize the relationship between environmental predictors and ecoregions.

Future climate change scenarios. We investigated the changes in SOC stocks until 2100 under SSP126 and SSP585 climate change scenarios of CMIP ${ }^{18,38}$. The increase in atmospheric $\mathrm{CO}_{2}$ is expected to increase temperature and change precipitation averages. We obtained maps of mean air temperature and precipitation from National Climate Assessment (https://nca2014.globalchange.gov/highlights/report-findings/future-clima te) and GFDL-ESM4 models (NOAA, National Oceanic and Atmospheric Administration) for every 10 years from 2030 to 2100 and used the GWR model to explore the effect of these changes on SOC stocks. Briefly, all the model predictors were kept constant with exception of temperature and precipitation (obtained from GFDLESM4 predictions), then the model was run to produce SOC maps. The generated SOC stock maps were also compared with GFDL-ESM4 model SOC stock maps for current and future climate change scenarios (CMIP6, https://esgf-node.llnl.gov/projects/cmip6/). This model was chosen because produced better predictions of SOC stocks in American biomes compared to other Earth System Models ${ }^{4}$. The maps were subtracted (e.g., 2100 SOC map for SSP126 scenario-current SOC map) for generate SOC stocks difference maps and those were used for comparing the differences between scenarios. All modelling processes were performed using R v. 3.6.1 ${ }^{39}$.

\section{Data availability}

The data that support the findings is available on request and the R code used in this study is on GitHub (https:// github.com/D9989/Geospmodel). 
Received: 30 October 2020; Accepted: 1 March 2021

Published online: 19 March 2021

\section{References}

1. Lal, R. Soil carbon sequestration impacts on global climate change and food security. Science 304, 1623-1627 (2004).

2. Batjes, N. H. Total carbon and nitrogen in the soils of the world. Eur. J. Soil Sci. 47, 151-163 (1996).

3. Luo, Y. et al. Toward more realistic projections of soil carbon dynamics by Earth system models. Glob. Biogeochem. Cycles 30, 40-56 (2016).

4. Todd-Brown, K. E. O. et al. Causes of variation in soil carbon simulations from CMIP5 Earth system models and comparison with observations. Biogeosciences 10, 1717-1736. https://doi.org/10.5194/bg-10-1717-2013 (2013).

5. Carvalhais, N. et al. Global covariation of carbon turnover times with climate in terrestrial ecosystems. Nature 514, $213-217$. https://doi.org/10.1038/nature13731 (2014).

6. Friedlingstein, P. et al. Persistent growth of CO2 emissions and implications for reaching climate targets. Nat. Geosci. 7, 709-715. https://doi.org/10.1038/ngeo2248 (2014).

7. Burke, E. J., Hartley, I. P. \& Jones, C. D. Uncertainties in the global temperature change caused by carbon release from permafrost thawing. CRYOSPHERE 6, 1063-1076. https://doi.org/10.5194/tc-6-1063-2012 (2012).

8. Varney, R. M. et al. A spatial emergent constraint on the sensitivity of soil carbon turnover to global warming. Nat. Commun. 11, 5544. https://doi.org/10.1038/s41467-020-19208-8 (2020).

9. O’Rourke, S. M., Angers, D. A., Holden, N. M. \& McBratney, A. B. Soil organic carbon across scales. Glob. Change Biol. 21, 3561-3574 (2015)

10. Rossel, R. V. et al. Continental-scale soil carbon composition and vulnerability modulated by regional environmental controls. Nat. Geosci. 12, 547-552 (2019).

11. Gomes, L. C. et al. Modelling and mapping soil organic carbon stocks in Brazil. Geoderma 340, 337-350 (2019).

12. Weintraub, S. R. et al. Leveraging environmental research and observation networks to advance soil carbon science. J. Geophys. Res. Biogeosci. 124, 1047-1055 (2019).

13. Poloczanska, E., Mintenbeck, K., Portner, H. O., Roberts, D. \& Levin, L. A. in 2018 Ocean Sciences Meeting. (AGU).

14. Houston, J. R. New 2019 sea level projections by the Intergovernmental Panel on Climate Change. Shore \& Beach 88, 37 (2020).

15. Staff, S. S. \& Loecke, T. Rapid Carbon Assessment: Methodology, Sampling, and Summary. (2016).

16. Hinson, A. L. et al. The spatial distribution of soil organic carbon in tidal wetland soils of the continental United States. Glob. Change Biol. 23, 5468-5480 (2017).

17. Kusler, J. A. Wetland creation and restoration: the status of the science (Island Press, 2012).

18. Pachauri, R. K. et al. Climate change 2014: synthesis report. Contribution of Working Groups I, II and III to the fifth assessment report of the Intergovernmental Panel on Climate Change. (Ipcc, 2014).

19. Doetterl, S. et al. Soil carbon storage controlled by interactions between geochemistry and climate. Nat. Geosci. 8, 780-783 (2015).

20. Yang, Y. et al. Storage, patterns and controls of soil organic carbon in the Tibetan grasslands. Glob. Change Biol. 14, 1592-1599 (2008).

21. Giardina, C. P., Litton, C. M., Crow, S. E. \& Asner, G. P. Accelerated soil carbon loss does not explain warming related increases in soil CO2 efflux. (2014)

22. Erwin, K. L. Wetlands and global climate change: the role of wetland restoration in a changing world. Wetlands Ecol. Manage. 17, 71 (2009).

23. Notaro, M., Vavrus, S. \& Liu, Z. Global vegetation and climate change due to future increases in CO2 as projected by a fully coupled model with dynamic vegetation. J. Clim. 20, 70-90 (2007).

24. Sykes, M. T. Climate change impacts: Vegetation. eLS (2009).

25. Liu, J. C. et al. Particulate air pollution from wildfires in the Western US under climate change. Clim. Change 138, 655-666 (2016).

26. Stevens-Rumann, C. S. \& Morgan, P. Tree regeneration following wildfires in the western US: a review. Fire Ecology 15, 15 (2019).

27. Wieder, W. R. et al. Explicitly representing soil microbial processes in Earth system models. Glob. Biogeochem. Cycles 29, 1782-1800 (2015).

28. Wills, S., Loecke, T., Sequeira, C., Teachman, G., Grunwald, S., \& West, L. T. "Overview of the US rapid carbon assessment project: sampling design, initial summary and uncertainty estimates." In Soil carbon, pp. 95-104. Springer, Cham, (2014).

29. Omernik, J. M. \& Griffith, G. E. Ecoregions of the conterminous United States: evolution of a hierarchical spatial framework. Environ. Manage. 54, 1249-1266 (2014).

30. Sequeira, C. H., Wills, S. A., Seybold, C. A. \& West, L. T. Predicting soil bulk density for incomplete databases. Geoderma 213 , 64-73 (2014).

31. Schruben, P. G. A., Bawiec, R. E., King, W. J., Beikman, P. B. \& Helen, M. Geology of the Conterminous United States at 1: 2,500,000 Scale--A Digital Representation of the 1974 PB King and HM Beikman Map. (1994).

32. Gesch, D., Oimoen, M., Zhang, Z., Meyer, D. \& Danielson, J. Validation of the ASTER global digital elevation model version 2 over the conterminous United States. Int. Arch. Photogramm. Remote Sens. Spatial Inf. Sci 39, B4 (2012).

33. ArcGIS version 10, Environmental Systems Research Institute, Inc., Redlands, CA, USA (2014).

34. Zhang, Z. Variable selection with stepwise and best subset approaches. Ann Transl Med 4, 136, https://doi.org/10.21037/atm.2016. 03.35 (2016).

35. Lu, B., Charlton, M., Harris, P. \& Fotheringham, A. S. Geographically weighted regression with a non-Euclidean distance metric: a case study using hedonic house price data. Int. J. Geogr. Inf. Sci. 28, 660-681 (2014).

36. Mishra, U. \& Riley, W. J. Alaskan soil carbon stocks: spatial variability and dependence on environmental factors. Biogeosciences 9, 3637-3645. https://doi.org/10.5194/bg-9-3637-2012 (2012).

37. Fotheringham, A. S., Brunsdon, C. \& Charlton, M. Geographically weighted regression: the analysis of spatially varying relationships (John Wiley \& Sons, 2003)

38. Eyring, V. et al. Overview of the Coupled Model Intercomparison Project Phase 6 (CMIP6) experimental design and organization. Geosci. Model Dev. 9, 1937-1958 (2016).

39. R Core Team. R: A language and environment for statistical computing. R Foundation or Statistical Computing, Vienna, Austria. URL https://www.R-project.org/ (2019).

\section{Acknowledgements}

We thank the USDA National Resources Conservation Service for the data used for the modelling process and the support describing data acquisition and quality assurance. Efforts of U. Mishra and S. Gautam were supported by the Joint BioEnergy Institute supported by the Office of Science, Office of Biological and Environmental Research, of the U.S. Department of Energy under Contract No. DE-AC02-05CH11231. Sandia National Laboratories is a multimission laboratory managed and operated by National Technology and Engineering Solutions of Sandia, 
LLC, a wholly owned subsidiary of Honeywell International, Inc., for the U.S. Department of Energy's National Nuclear Security Administration under contract DE-NA-0003525.

\section{Author contributions}

D.R.P.G.: Data processing, spatial modelling, manuscript preparation. U.M.: Manuscript preparation and review. S.W.: Data acquisition, data quality assurance description and manuscript review. S.G.: GFDL-ESM4, CMIP6 data processing and manuscript review.

\section{Competing interests}

The authors declare no competing interests.

\section{Additional information}

Supplementary Information The online version contains supplementary material available at https://doi.org/ 10.1038/s41598-021-85992-y.

Correspondence and requests for materials should be addressed to D.R.P.G.

Reprints and permissions information is available at www.nature.com/reprints.

Publisher's note Springer Nature remains neutral with regard to jurisdictional claims in published maps and institutional affiliations.

(c) (i) Open Access This article is licensed under a Creative Commons Attribution 4.0 International License, which permits use, sharing, adaptation, distribution and reproduction in any medium or format, as long as you give appropriate credit to the original author(s) and the source, provide a link to the Creative Commons licence, and indicate if changes were made. The images or other third party material in this article are included in the article's Creative Commons licence, unless indicated otherwise in a credit line to the material. If material is not included in the article's Creative Commons licence and your intended use is not permitted by statutory regulation or exceeds the permitted use, you will need to obtain permission directly from the copyright holder. To view a copy of this licence, visit http://creativecommons.org/licenses/by/4.0/.

(C) The Author(s) 2021 